Viso - Cadernos de estética aplicada Revista eletrônica de estética

ISSN 1981-4062

No 24, jan-jun/2019

http://www.revistaviso.com.br/
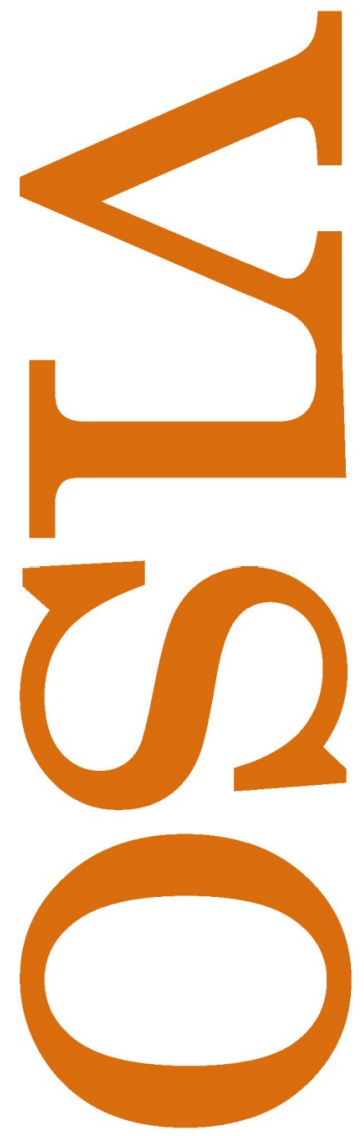

\title{
Palimpsestos sonoros em Savannah Bay, de Marguerite Duras Diego Reis
}

Universidade Federal do Rio de Janeiro (UFRJ)

Rio de Janeiro, Brasil 


\section{RESUMO}

Palimpsestos sonoros em Savannah Bay, de Marguerite Duras

Este ensaio tem como objetivo propor uma leitura da peça Savannah Bay, de Marguerite Duras, como uma espectropoética, isto é, concebida como modo de trabalhar o elemento espectral em sua composição via procedimentos sonoros e imagéticos específicos. Pautada pela fragmentação sonora, pela polifonia, pela duplicação vocal e figural, esta peça teria como traço fundamental a ênfase na dimensão auditiva e no universo acústico das operações características de meios sonoros, o que resultaria na criação de zonas de tensão entre temporalidade e espacialidade, matéria sonora das palavras e imagem. Para além da camada semântica, aqui a voz é pensada não apenas com a força de choque de um objeto material, mas também como o lugar de uma ausência que, nela, se transforma em presença. Esta espectropoética se configuraria então como exercício de experimentação vocal e de escuta marcado por traço lacunar, por reduplicações, ressonâncias e espelhamentos que caracterizaria a indeterminação da ausência-presença como procedimento formal privilegiado desta dramaturgia.

Palavras-chave: dramaturgia contemporânea - poéticas da cena - Marguerite Duras - escritura sonora - espectropoética

\section{ABSTRACT}

\section{Sound Palimpsets in Savannah Bay, by Marguerite Duras}

This essay aims to propose a reading of Savannah Bay by Marguerite Duras as a spectropoetic, that is, conceived as a way of working the spectral element in its composition by way of specific sonorous and imaging procedures. Guided by sonorous fragmentation, polyphony, vocal and figural duplication, this work would have as its fundamental trait the emphasis on the auditory dimension and the acoustic universe of the operations characteristic of sound media, which would result in the creation of zones of tension between temporality and spatiality, sound matter of words and images. Beyond the semantic layer, the voice is thought not only as the "shock force" of a material object, but also as the place of an absence that in it becomes a presence. This spectropoetics would then be configured as an exercise of vocal experimentation and listening marked by lacunar trait, by reduplications, resonances and mirroring that would characterize the indetermination of absencepresence as a privileged formal procedure of this dramaturgy.

Keywords: contemporary dramaturgy - poetics of the scene - Marguerite Duras - sound writing spectropoetics 


\section{REIS, D. "Palimpsestos sonoros em Savannah Bay, de Marguerite Duras". In: Viso: Cadernos de estética aplicada, v. XII, n. 24 (jan-jun/2019), pp. 133-147.}

DOI: $10.22409 / 1981-4062 / v 24 i / 314$

Aprovado: 20.10.2018. Publicado: 30.06.2019.

(C) 2019 Diego Reis. Esse documento é distribuído nos termos da licença Creative Commons Atribuição-NãoComercial 4.0 Internacional (CC-BY-NC), que permite, exceto para fins comerciais, copiar e redistribuir o material em qualquer formato ou meio, bem como remixá-lo, transformá-lo ou criar a partir dele, desde que seja dado o devido crédito e indicada a licença sob a qual ele foi originalmente publicado.

Licença: http://creativecommons.org/licenses/by-nc/4.0/deed.pt_BR

Accepted: 20.10.2018. Published: 30.06.2019.

(C) 2019 Diego Reis. This document is distributed under the terms of a Creative Commons Attribution-NonCommercial 4.0 International license (CC-BY-NC) which allows, except for commercial purposes, to copy and redistribute the material in any medium or format and to remix, transform, and build upon the material, provided the original work is properly cited and states its license.

License: http://creativecommons.org/licenses/by-nc/4.0/ 
Fantôme vagissant, on ne sait d'où venu,

Qui caresse l'oreille et cependant l'effraie.

Baudelaire

Através da força de sua voz adivinha-se outra força...

Duras

Em entrevista a Helène Cixous intitulada Sobre Marguerite Duras, de outubro de 1975, Foucault assinalaria sobre os trabalhos de Duras o traço de:

uma memória que foi inteiramente purificada de qualquer lembrança e que não passa de uma espécie de bruma, remetendo perpetuamente à memória, uma memória sobre a memória, e cada memória apagando qualquer lembrança, e isso infinitamente. ${ }^{1}$

Se até aquele momento livros que marcariam inextrincavelmente a sua recepção crítica como $\mathrm{O}$ amante e peças como Savannah Bay e $\mathrm{A}$ dança da morte ainda não haviam sido escritos, um aspecto interessante, porém, ressaltado por Foucault, já atravessava os seus trabalhos. O jogo permanente de apagamento ou o trabalho a partir da "memória do

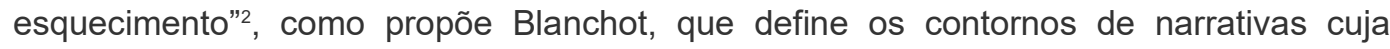
dimensão fantasmática parece menos devedora de uma imagem evanescente e instável do que de um procedimento de escrita ancorado em uma trama da voz.

Vozes desencarnadas, errantes ou perdidas que delineiam o andamento da ação e do ritmo nos filmes também. Lembre-se, por exemplo, das vozes extra-quadro de Hiroshima mon amour, de 1959-60, seguidas por longo silêncio. Ou da orquestração de melodias sobrepostas em India Song, de 1975, filme escrito e dirigido por Duras. Esta polifonia complexa, amplificada a partir dos anos de 1970, mobiliza múltiplas vozes que deslocam de maneira acelerada o foco e os tempos narrativos, criando uma espécie de mise en abyme vocal. O espelhamento interno e as superposições de camadas sonoras acentuam não somente o caráter autorreflexivo nos filmes, mas produzem um estranho efeito de simultaneidade também no teatro, como em Savannah Bay, para citar um exemplo. Aí se trata de uma atriz em cena que escuta uma jovem mulher e enuncia sucessivas versões de uma estória que mescla o relato biográfico e a atuação cênica, num duplo indiscernível.

Não é fortuito que o jogo com os tempos verbais das narrativas produza uma sucessão temporal vertiginosa de duração não identificável e que virtualiza, por isso mesmo, não somente o passado rememorado, mas o presente das próprias personagens, desordenado e incerto, como se houvesse uma lacuna preenchida a todo momento por certezas fictícias. A alternância do passado, de um passado posterior e do presente da lembrança, apesar da aparência estratégica de presentificação do passado como reflexo de uma memória sem lastro, à margem da realidade - mas não imune a ela -, reforça o desdobramento temporal e uma suposta narração/enunciação "objetiva" dos fatos - com que se joga também ativamente na estruturação dos seus romances. Coincidência esta que gemina a perspectiva "de quem de repente se vê como outra, como outra seria vista, 
de fora"s, como em $\mathrm{O}$ amante, ou mesmo de quem se encontra diante do relato "da memória falha de Madeleine", em Savannah Bay, acompanhando o choque frequente entre a identidade coincidente da atriz e da narradora, e sua estranheza ininterrupta, "como se tivesse ouvido o que acabara de dizer [no passado] dito por outra [no presente]". ${ }^{4}$

É nesse lugar ambíguo, em que o desdobramento sonoro e visual cria uma tensão conflitiva, que Savannah Bay encontra sua força disruptiva nas figuras e nas vozes femininas. Publicada em 1982 e encenada no Théâtre du Rond-Point no ano seguinte, em Paris, a peça é uma narrativa a duas vozes entre uma jovem e Madeleine, velha atriz que relata a morte de outra jovem mulher na Baía de Savannah após dar à luz uma criança. O diálogo com e sobre essa mulher ausente se torna objeto de interlocução de ambas, na bruma de sua presença evanescente.

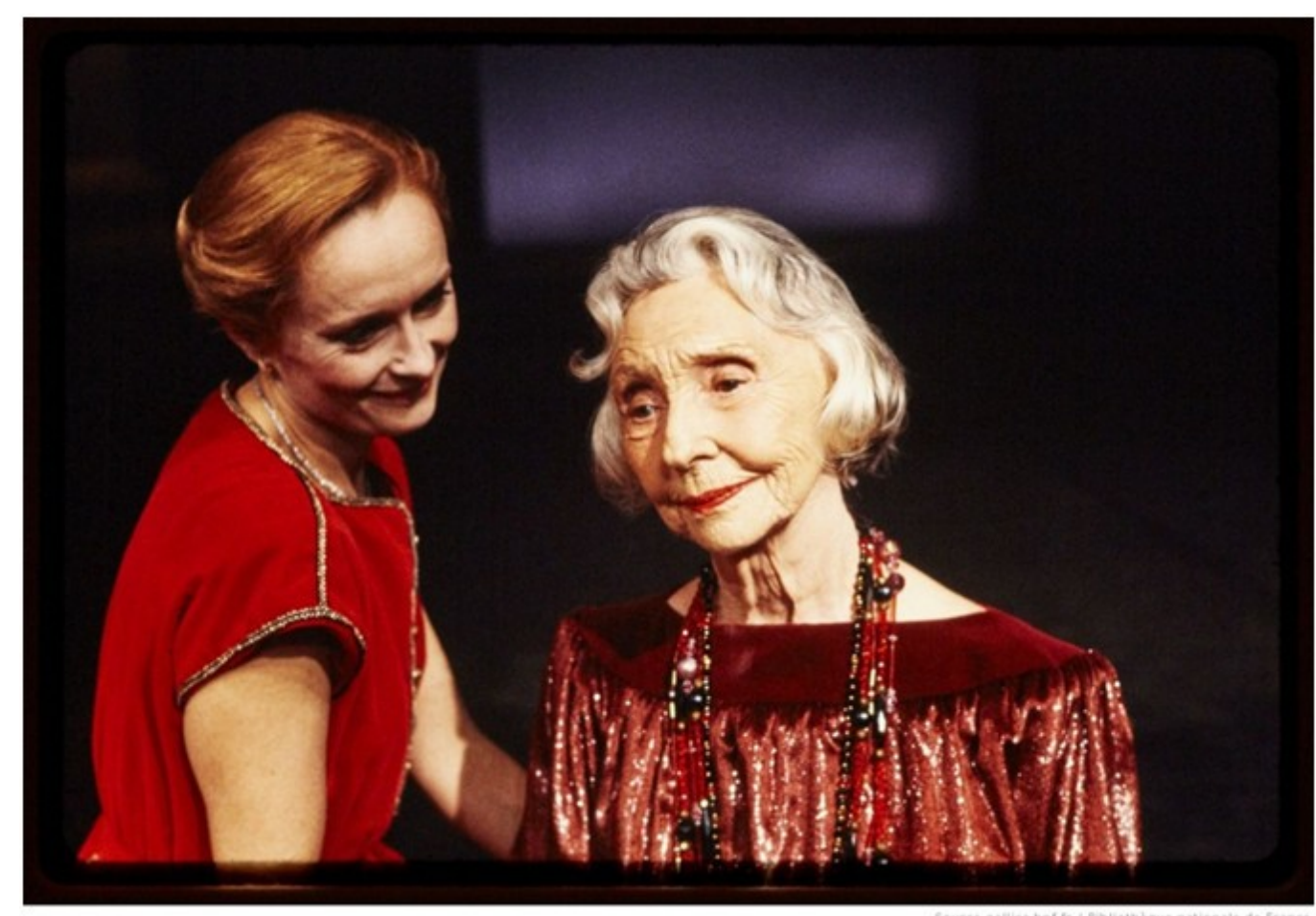

Figura 1. Martine Chevallier e Madeleine Renaud. Théâtre du Rond-Point, 1983. Acervo BnF.

A peça, que se configura ela mesma como um duplo, com as versões de 1982 e de 1983 publicadas conjuntamente - esta última acrescida das variantes estabelecidas à ocasião da encenação dirigida por Duras -, é movida por um princípio de perda: sabe-se desde as primeiras indicações textuais da "recordação fragmentária" que constituirá o seu andamento. Aqui poderia valer ainda a afirmação da narradora de $\mathrm{O}$ amante, como uma espécie de epígrafe, em meio ao rumor com que a peça se abre: "a história da minha vida não existe. Ela não existe. Nunca há um centro. Nem caminho, nem linha”. ${ }^{5}$ 
Poderíamos, por outro lado, desconfiar um pouco desta afirmação tomada poeticamente em sua forma negativa. Pois se a história de vida que se pretende restituir ao longo de Savannah Bay existe apenas nos retalhos soltos de relatos cerzidos e abandonados reiteradamente, e as linhas genealógicas da busca da "identidade" da jovem mulher se esgarçam a tal ponto que se torna indiscernível a identificação de sua linhagem, há ainda um caminho elíptico que se desenha, como as torrentes da baía de Savannah. ${ }^{6}$

Este caminho passa por uma outra margem, delineada pelo trânsito do foco narrativo flutuante entre primeira e terceira pessoas. ${ }^{7} \mathrm{~A}$ enunciação em terceira pessoa se, por um lado, reforça o traço épico pela via do relato da jovem morta, de quem se fala obstinadamente, por outro lado, abandona qualquer distanciamento ao assumir ora a vocalização de Madeleine, ora a da jovem mulher, ambas manifestamente ausentes da cena narrada. ${ }^{8}$ Ausência que se expressa no texto pelas recorrentes anáforas e repetições que, ao longo da peça, se tornam mais fluidas não pela lembrança, mas pela frequência recitativa.

Daí um outro registro não menos frequente: o emprego do condicional passado. A recorrência deste tempo da dúvida e da suspensão, que imprime caráter hipotético ao que é enunciado, estranhamente desrealizado no próprio ato de sua enunciação, opera como uma espécie de madeleine-reversa de Proust que, mais do que acionar o dispositivo de uma memória involuntária, reforça os oximoros e a autorreferencialidade do teatro. Como não há certeza alguma, resta um passado inconcluso, que se estende indefinidamente pelos meandros de uma "memória falha"

Madeleine: Ele teria chegado perto dela, ela o teria visto no último minuto, quando ele já subira na pedra. Ele a olharia por muito tempo e depois expressaria seu assombro de vê-la ali, naquele lugar do mundo, em cima daquela pedra branca, tão longe..$^{10}$

Reforço da hesitação, ademais, pela proliferação de advérbios de dúvida - como "talvez" -, que marca a incerteza e a oscilação do discurso das duas mulheres. Repetição em relevo, reminiscência lenta. O que torna aparente o mecanismo inventivo de uma "memória sem lembrança", de que falava Foucault na entrevista a Cixous, pronta a preencher as lacunas do jogo de erotismo e aniquilação que constitui o relato. 


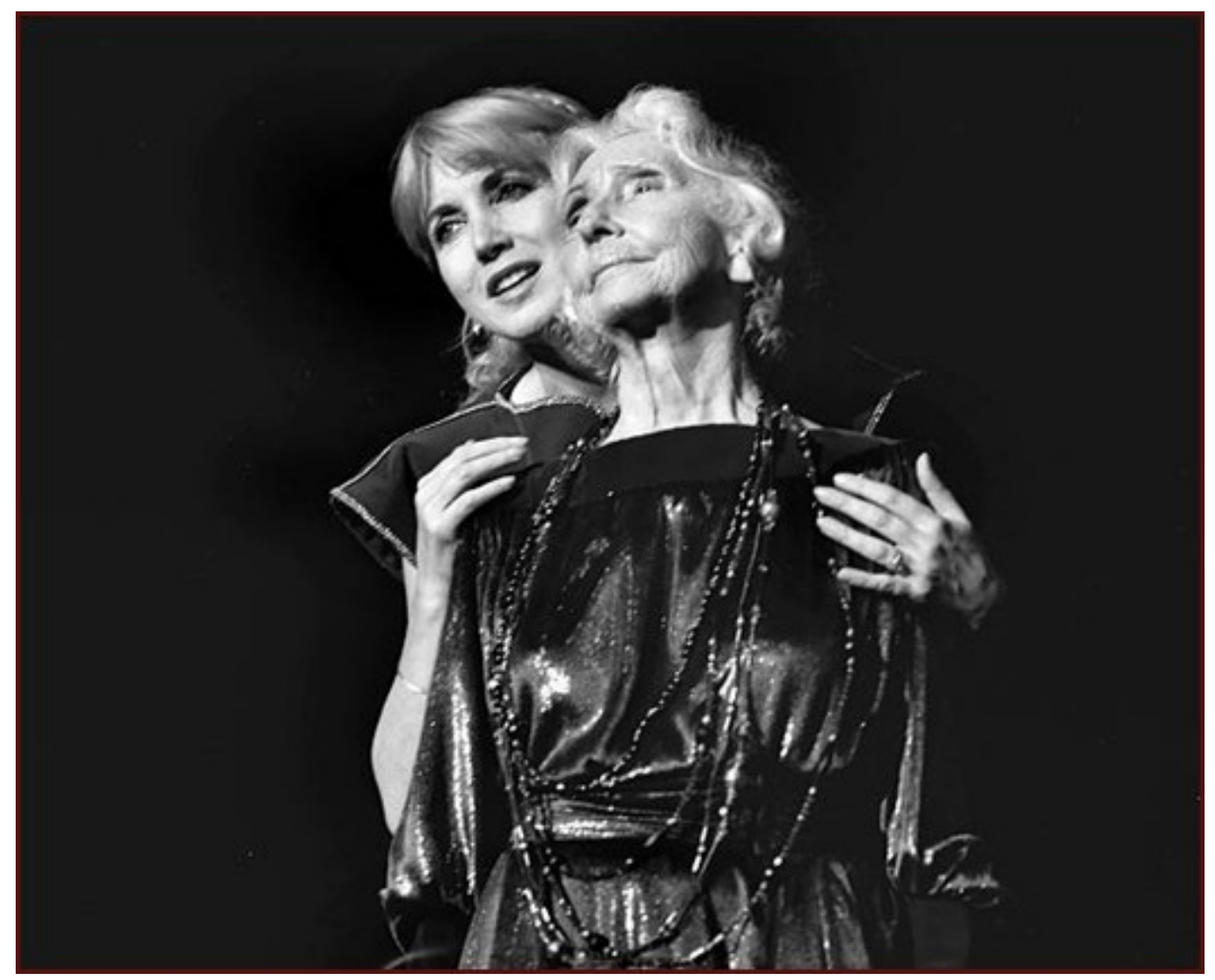

Figura 2. Bulle Ogier e Madeleine Renaud. Théâtre du Rond-Point, 1983. Acervo BnF.

O jogo de montagem da narrativa, modificada em sucessão temporal acelerada pelo imaginário ativo das vozes em triangulação - de Madeleine, da jovem mulher e da morta -, permitiria, como nota Marcelle Marini no ensaio La mort d'une érotique, de 1983, a experimentação do que o "real tem de insuportável para marcar seu poder de transformação". ${ }^{11}$ Procedimento que retorna em uma série de outros romances e novelas, como O homem sentado no corredor, de 1980, em um misto de terror e fascinação da violência erotizada por um "eu-olho" que, se não pode tudo penetrar, adivinha, "além do visível do homem e da mulher"12, preenchendo-a de imagens, a cena de sexo e de espancamento que se está em vias de descrever.

Ora, este entrecruzamento do desejo e da morte, cuja tangente é a fantasia do desaparecimento do objeto de que falam, traz ainda outro ponto de convergência em Savannah Bay - este menos aparente: a coincidência entre a busca de uma identidade que é levada adiante por uma jovem mulher - anônima - e a identidade inválida da atriz consagrada para quem o seu fazer tornou-se o seu modo de existir. Ligadas por uma mesma "pedra branca", cuja imagem é regularmente aventada - e talvez seja a de uma sepultura $^{13}-$, a jovem se coloca na cena de uma repetição: a da narrativa em diferença da mesma estória. Este ritual que as une, "baseado na deterioração da memória de Madeleine"14, é o da representação (cênica) de um passado comum, seja pela via do 
texto teatral que desempenham, seja pela construção da memória da personagem mais jovem a partir de uma escuta atenta da velha atriz.

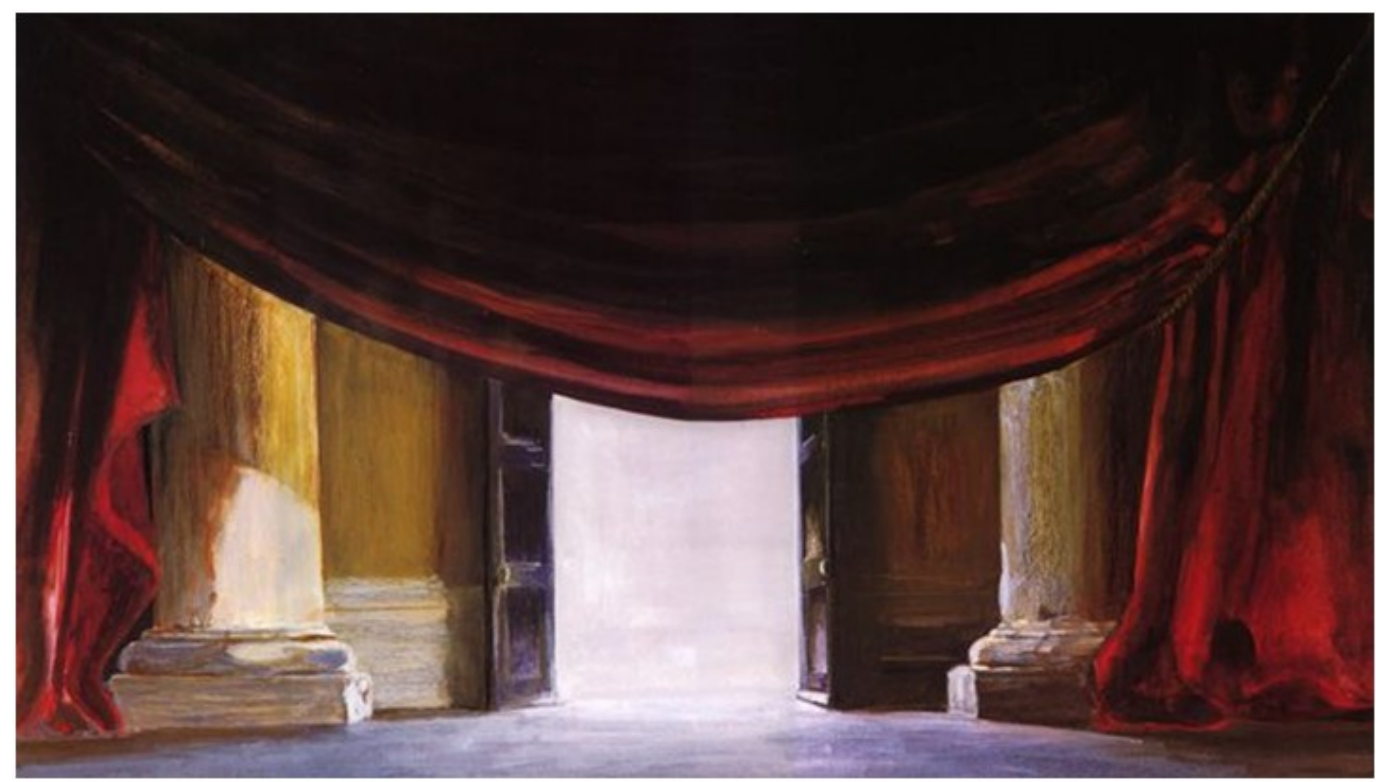

Figura 3. Esboços para o cenário. Pintura de Roberto Platé. 60x40 cm. Acervo BnF.

Trata-se, portanto, do exercício de uma escuta espectral. Escuta que se funda num movimento digressivo, numa lacuna a partir da qual a peça se erige: uma obliteração involuntária da memória que obstaculiza qualquer certeza. Ou ainda, a explicitação de que o teatro e a escrita são os lugares próprios da virtualidade, como a cena da memória e seus mitos de origem. Lembrança-ficção e "compulsão à repetição" que, por vezes, aproximam as personagens de verdadeiros estados oníricos, que mesclam o desamparo, a angústia e a desorientação.

Há, porém, uma chamada recorrente à "realidade" na peça. É interessante notar como a música é operada de modo a se contrapor a estes estados. Aliás, desde o início da peça, a entonação neutra das vozes das atrizes pretende, por um lado, reafirmar o afastamento dos fatos e certa impessoalidade, mas, por outro lado, contrasta no tom quase melancólico que, desde as primeiras linhas, marca o compasso da peça. Esta "cisão subjetiva" e a ênfase na voz narrativa ao longo do texto têm como sustentação, é bem verdade, uma outra dissociação permanente: aquela entre som, voz e imagem.

Não é difícil perceber, então, a importância da música em Savannah Bay. Da canção de Edith Piaf que abre a peça (que se inicia com a audição da canção "les mots d'amour") ao quinteto de Schubert, presente na encenação, e enxertado na segunda versão do texto, o lugar e o papel destas interferências musicais não têm a função meramente de sublinhar as imagens verbais ou de criar uma atmosfera, como poderia parecer de imediato. Motivo recorrente nos romances, vale lembrar, a título de exemplo, da "valsa desesperada" em O amante da China do Norte ${ }^{15}$, de 1991, ou da "voz mecânica" do 
gramofone de Joseph em Uma barragem contra o Pacífico ${ }^{16}$, de 1950 , bem como das cenas regulares de escuta musical nas peças, marcadas pela imprevisibilidade e pela interrupção.

Se nas duas versões de Savannah Bay a canção Les mots d'amour de Piaf, logo no início, prenuncia o desatino amoroso que se descortina no decorrer da peça, uma diferença significativa merece ser assinalada. Enquanto na primeira versão a música só se inicia alguns instantes após a entrada de Madeleine, em meio a um rumor de vozes jovens que são ouvidas "com muita intensidade", na versão posterior, na penumbra de um "palco quase vazio", a voz do disco com orquestra se apresenta imediatamente, como um golpe. A escuta tensa do burburinho de vozes entremeadas pelos versos de Piaf, cuja voz, apesar do esforço, não é reconhecida pela velha dama, se desloca em direção a uma outra escuta. A escuta-dupla, que é o ponto de partida da versão encenada, coloca lado a lado as duas mulheres imóveis, vistas em sua escuta, sob o fundo da música altíssima. Ali, o contraste entre o eco visual e o eco sonoro encontra no mínimo da cena uma outra intensidade: a acústica - do volume quase ensurdecedor que preenche o espaço de uma ausência.

É na versão encenada, ainda, que uma música ausente da primeira passa a figurar como elemento de insuspeita importância na escritura cênico-dramatúrgica. Trata-se do adágio do quinteto em dó maior de Schubert, uma das últimas peças escritas pelo compositor austríaco. As longas linhas melódicas do adágio, com o predomínio do contraponto, reforçam a expressividade de cenas atravessadas pela evidência da teatralidade, em que qualquer coisa de mecânico e artificial parece saltar aos olhos e aos ouvidos. Contraponto, é bem verdade, que cria uma espécie de efeito de suspensão, decorrente da paisagem ficcional pungente que se atrita ao relato seco das mulheres. Seria interessante associar, então, este contraponto da melodia em camadas do quinteto de Schubert à polifonia com que trabalha a cena durasiana. E aos silêncios como contratempo, tanto aqueles expressos pelas indicações didascálicas, como aqueles ligados à estrutura interna do texto por meio dos sinais gráficos, das reticências e da descontinuidade em sua marcha deambulante.

Narrar uma catástrofe com e contra o silêncio, que se enuncia com dificuldade na forma problemática de um corpo amnésico e resistente à restituição fidedigna, ou jovem demais para lembrar o que se passou, é a tarefa que as duas mulheres teriam que levar a cabo. E isso no jogo espelhado da escrita e do apagamento, da voz cindida e da emissão reduplicada. O diálogo elíptico, fraturado pelo silêncio, reforça nesse jogo a separação de uma e outra. Como se de ambos os lados houvesse algo como um segredo a ser desvendado, escondido sob a bruma da "pedra branca", e que oporia Madeleine e sua identidade ambígua à jovem mulher, anônima, cujo nascimento coincide "de maneira dramática com esse acontecimento" que culmina na morte da jovem na Baía de Savannah. Daí as frases sintéticas, entrecortadas pelas suspensões e pelo ritmo ralentado - como se todas as respostas estivessem ali, nos corpos, mas fossem 
ilegíveis, dificilmente nomeáveis diante do vazio em direção ao qual as mulheres se projetam. As palavras de Benjamin sobre a imagem do Angelus Novus, de Klee, bem caberiam aqui. Nisto que, entrevisto pelas personagens, é continuamente barrado ao leitor-espectador pelos cancelamentos rítmicos ou semânticos, pois, no universo intraficcional, "onde nós vemos uma cadeia de acontecimentos, ele vê uma catástrofe única, que acumula incansavelmente ruína sobre ruína e as dispersa a nossos pés". ${ }^{17}$

É neste compasso lento de uma trama descontínua, narrada e interrompida pelos silêncios, que, aos poucos, se ligam os fios labirínticos de uma descendência insinuada: a jovem mulher seria a neta de Madeleine. A dramatização das identidades, porém, que se instabilizam por meio da memória-em-estilhaços do autorreconhecimento continuamente cancelado, é ampliada pela ênfase na paisagem cênica. As versões coexistentes e as vozes que se diferenciam de si mesmas por estranho princípio de alteridade são indícios de identidades performativamente construídas, por se tratar, aí, no limite, sempre do jogo - o do teatro -, no qual o "eu é um outro".

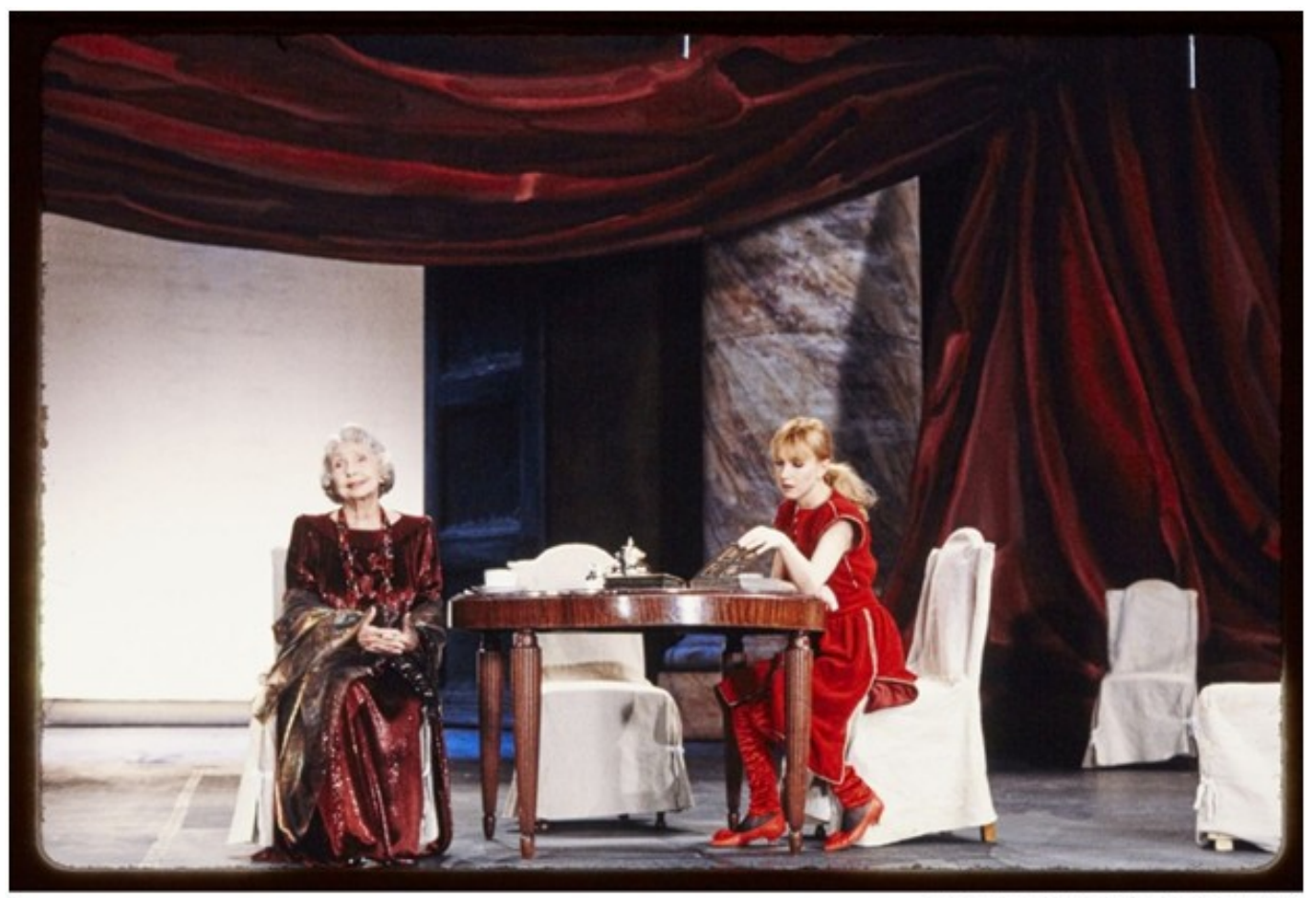

Figura 4. Martine Chevallier e Madeleine Renaud. Théâtre du Rond-Point, 1983. Acervo BnF.

Não é de surpreender que, a despeito do extravio indicado desde as primeiras linhas, Madeleine não deixe de conduzir o "jogo da memória". De tudo o que parece ter sido perdido no labirinto da memória, permanece inequívoca uma informação do passado - a de sua identidade funcional: 
Madeleine: [...] eu era atriz. Era o que eu fazia. Atriz.

Silêncio. Depois, as palavras:

Mulher Jovem: Atriz de teatro.

Madeleine: Sim.

Mulher Jovem (tempo): Nada mais.

Madeleine (tempo): Nada.

Silêncio. ${ }^{18}$

E, com uma irônica autoconsciência da representação, pode-se até afirmar, apontando em determinado momento à sua volta, ainda que de modo dramaticamente hesitante: "Madeleine: Mas aqui é um teatro"19, e acrescentando adiante que "o teatro está cheio, a plateia pagou, nós lhe devemos o espetáculo". ${ }^{20}$ Efeitos narrativos da diegese sublinhados, portanto, que resultam na exposição dos procedimentos da enunciação teatral e de sua prática significante ao leitor/espectador.

A impossibilidade de coincidir com o passado, que é necessariamente representação, acentua a proliferação das narrativas. Se, como assinala Ecléa Bosi, "a memória é a faculdade épica por excelência" ${ }^{21}$, na peça o lugar do épico não se resume a um rememorar que teria por contraponto o esquecimento. A memória aqui é moto do jogo cênico, "tornado possível pela despersonalização e pela desapropriação da memória" no "jogo da textualidade". ${ }^{22}$ Jogo que se converteria não por acaso em dupla ficção: na rememoração de um texto que é, simultaneamente, teatral e biográfico. Daí a afirmação tão lúcida da velha dama: "Madeleine: Sim, começa-se a duvidar do que aconteceu, de quem morreu, de quem continua vivo, de que livro era, de que cidade, de quem sofre, de quem conhece a história, de quem a fez....".

Afinal, a trama "toca da mesma maneira todas as memórias" ${ }^{23}$, pois, ao perdê-la, se instaura uma relação de "exterioridade" que possibilita a sua narração por qualquer voz e uma multiplicação das proposições. Segundo a análise de Susan Cohen, no ensaio A presença do nada, haveria uma "equivalência fundamental entre contar [raconter], lembrar-se, imaginar e fazer fiç̧ão". ${ }^{24}$ Pois se o "nada" é a matéria visível do jogo textual, toda ação de preenchimento estaria ancorada na ficcionalidade de um "como se" que não se realiza plenamente - e, por consequência, engendra outra versão de um texto possivel.

Mais uma vez, o que se repete retorna em diferença, como fluxo de uma produção infinita. Não é de estranhar, portanto, que este movimento espectral em Savannah Bay encontre no mar a sua figuração privilegiada. E não somente pelo movimento contínuo das ondas descrito por Madeleine e pelo modo como elas tocam a "pedra branca" - outra 
imagem que não cessa de ser mobilizada pelas vozes femininas. Mas também pelo fundo sonoro desse imenso vazio, fraturado pela pedra branca sobre a qual a morta aparece e desaparece, ora perdida na imensidão "do mar pesado que sustentava os corpos, muito profundo e muito azul" 25 , ora em contraste com a "matéria mineral", deitada de maiô preto na pedra ardente. É da sinfonia sonora das ondas quebrando, cujo movimento contínuo de aparição e desaparição revela ou oblitera a pedra, do silêncio e do marulho, a um só tempo, que uma "outra margem" se mostra. Aquela que desdobra o leito dos amantes no cenário funesto e da cena sensual bipartida entre o gozo dos amantes e a dor que liquida a memória. ${ }^{26}$

Esta camada acústica exterior, que interfere ativamente na narrativa das personagens, se constitui como uma paisagem sonora que não deve ser relegada a segundo plano. Isto porque a dimensão temporal difusa, configurada pela mescla de tempos verbais e pelas vozes duplicadas, com a clara intercessão entre presente e passado, encontra neste "envelope sonoro" um efeito imprescindível para a simbolização e a construção de uma estória remendada pelos ruídos, ecos e ressonâncias. A imagem fantasmática do som e a evocação constante das paisagens sonoras, quer seja das ondas do mar ou das canções de Piaf e de Schubert, tornam-se assim o modo de encenar deslocamentos das personagens, da alteridade e da estranheza diante da sucessão das linhas sonoras e dos lapsos que exigem a pausa e resultam na infiltração de um silêncio corrosivo. Cabe notar ainda que os fluxos sonoros parecem constituir quase uma outra narrativa, paralela, insinuada de antemão na cena de escuta pela qual a peça se inicia. Com o reforço que é operado, logo no primeiro diálogo, pela imagem do disco, do artefato técnico de reprodução musical, delicado como a memória, no qual qualquer arranhão corre o risco de se tornar uma falha e atrapalhar a qualidade sonora.

A memória-disco de Madeleine é a fonte emissora do relato de um passado aparentemente em-aberto, esburacado, apesar de sabermos que ele já ocorreu, e se expõe em conflito com as múltiplas versões ouvidas, mapeadas e co-produzidas pela mulher jovem. As duas narradoras femininas, ora em continuidade (como desdobramento de uma única voz), ora acentuando os traços de diferenciação interna (pelo entrechoque das possibilidades narrativas e rítmicas), produzem um caleidoscópio de imagens virtuais, fantasmáticas, ligadas à situação de uma escuta distante da fonte sonora. O que poderia ser lido como uma espécie de fonografia "visual", de quem deseja gravar no corpo, enquanto superfície de inscrição, uma memória externa, não-vivida, mas imprescindível para a própria auto-afirmação, e cujo contraponto é o intrincado mapa sonoro traçado como se as duas estivessem presentes na cena que narram. Tudo o que escutam, contudo, é o mar e o vento de cinzas que atravessa a paisagem, no jogo do desejo e do luto, "pela proliferação da palavra que a imagem não contém", ${ }^{27}$

Se a visão coloca em perspectiva o que é visto, exigindo certa distância em presença dos objetos, o som, por sua vez, espacializa o tempo pela criação de paisagens virtuais que aproximam o ouvinte da atmosfera do que é relatado, pela porosidade das fronteiras 
entre a percepção auditiva, a memória e a imaginação. E se a memória desconhece estas margens, o que permanece nesta espectropoética durasiana é a presença de uma ausência, triplamente referenciada: a jovem morta; a memória em migalhas de Madeleine; e a indiferenciação identitária da jovem mulher. $O$ desenho sonoro deste passado líquido, instanciado na Baía de Savannah, na trama fragmentada de amor e fúria repetida compulsivamente, adquire, portanto, o registro de uma onda sonora: a da dissipação e da proliferação da capacidade imagética ancorada no som. Daí a lembrança de Helène Cixous, ao fim da entrevista com Foucault, de que frequentemente nas narrativas de Duras, "se o olhar é cortado, ela tem orelha, então é de lá que isso retorna, isto é, aquilo que está fora retorna [rentre] - a voz é justamente isto que penetra". ${ }^{28}$

Penetra o texto de Savannah Bay como lâmina fina que fragmenta a narrativa em um caleidoscópio sonoro partido do início ao fim pela orquestração dos ruídos, das músicas de Piaf e de Schubert, e do murmúrio ininterrupto das vozes fantasmais que fendem a convergência das versões narradas. Gesto épico, como outro corte do texto-partitura, que se abre como réquiem e se fecha como fluxo, feito o barulho surdo de mar que atravessa a peça: essa linha d'água em ebulição, simultaneamente o fogo e o mar que Savannah nomeia.

\section{* Diego Reis é doutorando em filosofia pela UFRJ.}

${ }^{1}$ FOUCAULT, M.; CIXOUS, H. "Sur Marguerite Duras". In: FOUCAULT, M. Dits et Écrits I. Paris: Gallimard, 2001, p. 1630

2 "Oblieuse mémoire”. Cf. BLANCHOT, M. L'entretien infini. Paris: Gallimard, 1969, p. 459 et seq

${ }^{3}$ DURAS, M. O amante. Tradução de Denise Bottmann. São Paulo: Cosac Naify, 2012, p. 15.

${ }^{4}$ Idem. Savannah Bay. Tradução de Sieni Maria Campos. Rio de Janeiro: Ed. Record, 1983, p. 28.

${ }^{5}$ Idem. O amante. Op. cit., p. 10.

$6 \mathrm{Na}$ peça, duas mulheres exploram os meandros de suas memórias para evocar um acontecimento não testemunhado por nenhuma delas, mas que transforma completamente as suas vidas: o suicídio de uma jovem mulher em Savannah Bay, um dia após dar à luz a uma criança. Madeleine, sua velha mãe - e uma famosa atriz -, tenta se lembrar do ocorrido diante da jovem que a questiona reiteradamente. Mas, por conta da idade avançada, sua memória parece falhar. Entre reminiscências incertas e fabulação, silêncios e imobilidade, um diálogo se instaura entre as duas e traz à tona a obsessão do amor, da morte, da memória e do esquecimento inerentes à construção da narrativa.

7 Há, porém, na pequena indicação de abertura da peça uma passagem em segunda pessoa, assinada por "M.D". Espécie de indicação paratextual orientada pelo negativo, a interpelação traz o leitor para a posição de Savannah Bay, como convite ao "jogo da memória" que se apresentará na sequência. O dêitico "tu", deste modo, está no entrecruzamento de dois tempos, o passado e o presente, com a clara indicação de se tratar, ali, de um espetáculo "que a plateia pagou" e que "Ihe é devido".

${ }^{8}$ Como lembra Joseph Danan, este procedimento já se encontra, em 1977, em L'Éden cinema, peça na qual "a problemática do monodrama cruza de maneira manifesta com a do eu épico szondiano, por intermédio da voz da narradora de Suzanne." In: SARRAZAC, J.-P. (org). Léxico do 
drama moderno e contemporâneo. Tradução de André Telles. São Paulo: Cosac Naify, 2012, p. 114.

${ }^{9}$ Nesse sentido, afirma Madeleine: "[...] ...tudo é sempre como se... como se fosse possível...". DURAS, M. Savannah Bay. Tradução de Sieni Maria Campos. Rio de Janeiro: Record, 1983, p. 51.

10 Ibidem, p. 36.

${ }^{11}$ MARIANI, M. "La mort d'une érotique". In: Cahiers Renaud Barrault, n. 106. Paris: Gallimard, 1983, p. 54.

${ }^{12}$ DURAS, M. O homem sentado no corredor \& A doença da morte. Tradução de Vadim Nikitin. São Paulo: Cosac Naify, 2007, p. 25.

${ }^{13}$ É Duras quem sugere isto em entrevista junto ao cenógrafo Roberto Plate: "a pedra branca é uma sepultura para mim" [la pierre blanche, c'est une sépulture pour moi]. DURAS, M.; PLATE, R. "Le décor de Savannah Bay - Entretien". In: Cahiers Renaud Barrault, n. 106. Paris: Gallimard, 1983, p. 8.

${ }^{14}$ DURAS, M. Savannah Bay. Tradução de Sieni Maria Campos. Rio de Janeiro: Ed. Record, 1983. p. 25.

${ }^{15}$ Idem. O amante da China do Norte. Tradução de Denise Range Barreto. Rio de Janeiro: Ed. Nova Fronteira, 2006.

${ }^{16}$ Idem. Uma barragem contra o Pacífico. Tradução de Eloísa Araújo. São Paulo: Editora Arx, 2003.

${ }^{17}$ BENJAMIN, W. Magia e técnica, arte e política: ensaios sobre literatura e história da cultura. Tradução de Sérgio Paulo Rouanet. São Paulo: Brasiliense, 1987, p. 226.

${ }^{18}$ DURAS, M. Savannah Bay. Op. cit., p. 24.

19 Ibidem, p. 52.

${ }^{20}$ Ibidem, p. 57.

${ }^{21}$ BOSI, E. Memória e sociedade: Lembranças de velhos. São Paulo: Ed. USP, 1987, p. 48.

${ }^{22}$ COHEN, S. D. "La présence de rien". In: Cahiers Renaud Barrault, n. 106. Paris: Gallimard, 1983, p. 29.

${ }^{23}$ DURAS, M. Savannah Bay. Op. cit., p. 10.

${ }^{24}$ COHEN, S.D. Op. cit., p. 30.

${ }^{25}$ DURAS, M. Savannah Bay. Op. cit., p. 34.

${ }^{26}$ É interessante como a figuração do mar adquire importância inequívoca nos trabalhos de Duras. Aliás, os fluxos de água, de modo geral - rios, lagos, baías, mares. Quer seja nos filmes, nas peças ou nos romances, estas massas aquosas são actantes, que pautam, por vezes, o ritmo da narrativa. Assim, o mar agitado de Savannah Bay se diferencia do mar de A doença da morte, que imprime outro ritmo à narrativa. Em muitos dos trabalhos, além disso, a evocação ao universo hídrico já se encontra no título, como Vera Baxter ou les plages de l'Atlantique, de 1980; Les eaux et forêts, peça de 1965; ou o romance L'homme atlantique, publicado em 1982 e adaptado para o cinema por Duras um ano antes. Tome-se, por exemplo, uma passagem deste último. $\mathrm{O}$ movimento da memória e o movimento do mar nesta longa carta amorosa se confundem a ponto de tornar-se quase uma e mesma coisa: “Je l'ai pris et je l'ai mis dans le temps gris, près de la mer, je l'ai perdu, je l'ai abandonné dans l'étendue du film atlantique. Et puis je lui ai dit de regarder, et puis d'oublier, et puis d'avancer, et puis d'oublier encore davantage, et l'oiseau sous le vent, et la mer dans les vitres et les vitres dans les murs. Pendant tout un moment il ne savait pas, il ne savait plus, il ne savait plus marcher, il ne savait plus regarder. Alors je l'ai supplié d'oublier encore et encore davantage, je lui ai dit que c'était possible, qu'il pouvait y arriver. Il y est arrivé. II a avancé. II a regardé la mer, le chien perdu, l'oiseau sous le vent, les vitres, les murs. Et puis il est sorti du 
champ atlantique. La pellicule s'est vidée. Elle est devenue noire. Et puis il a été sept heures du soir le 14 juin 1981. Je me suis dit avoir aimé”. DURAS, M. L'homme atlantique. Paris: Les Éditions de Minuit, 1982.

${ }^{27}$ DURAS, M.; LAMY, S.; ROY, A. Marguerite Duras à Montréal. Paris: Éditions Spirale, 1981, p. 45.

${ }^{28}$ CIXOUS, H.; FOUCAULT, M. Op. cit., p. 1639. 